\title{
Improving agricultural competitiveness by setting priorities for investments in crop research: lessons from Zambia
}

by

\section{Choolwe Haankuku and Johann Kirsten}

Department of Agricultural Economics, Extension and Rural Development University of Pretoria, Pretoria 0002, South Africa

Office: Room 2.22, Agricultural Annex Phone: (+27-12) 4205769 Fax: (+27-12) 4203247

E-Mail: choolweh@yahoo.com

\begin{abstract}
Countries in Africa are pledging more resources for agricultural development and agricultural research, in line with the 2003 Maputo declaration. However, experts have reasoned that the quantity of resources is as important as the quality of spending. If resources are allocated efficiently, more could be achieved with the same resources. Ensuring an effective strategy and basis for prioritising crop research investments so as to improve productivity is a major challenge in Zambia and other African countries. This study investigates the economic returns of investment in crop research and sets priorities for research investment using the Dynamic Research Evaluation for Management (DREAM) model. The findings show that maize, soya beans, groundnuts, cotton, millet, sunflower and sorghum are the crops that should receive priority in terms of funding for research under the efficiency objective. However, the study showed that the allocation of financial resources towards crop research in Zambia is not aligned with the social and economic returns of that investment. Nonetheless,
\end{abstract}


positive returns from crop research investments were obtained, which suggests that investing in crop research is worthwhile but that attention needs to be paid to the appropriate research priorities. This is critical for improved competitiveness in Zambian agriculture. The study recommends further investment in and robust prioritisation of crop research, complemented by improved infrastructure, institutions and markets for a thriving agricultural sector.

Key words: Economic returns from agricultural research, Research priority setting, Agriculture R\&D Investment

\section{Introduction}

Despite widespread acknowledgement that investment in agricultural research is crucial for agriculture led economic development in countries such as Zambia (PRSP, 2002; Govereh et al., 2006), little has been said about how investment in agricultural research should be prioritised in order to increase agricultural productivity and maximise the returns from such activities given that the available resources are scarce. Furthermore, there has been little analysis of past performance and congruence between priorities and expenditure in the agricultural sector. As such, there is little consensus on what the strategy for stimulating agriculture research expenditure should look like (Govereh, Malawo, Lungu, Jayne, Chinyama \& Chilonda, 2009).

In order to enhance the performance of agricultural research in Zambia and to execute a strategy that will enhance agriculture growth through investment in agricultural research, this paper attempts to ascertain whether the financial allocation to crop research is efficient and to identify the priority crops for research investment. It also seeks to determine the economic returns of crop research expenditure on producers and consumers. The study tests the hypothesis that the financial outlay in agricultural crop research is not efficiently aligned with the returns from agricultural research nor with the nation's agricultural production potential.

The paper first presents a contextual overview of Zambia's agricultural sector and its agricultural budget and then explains the methodology applied in this study. Section 4 of the paper presents a detailed overview of crops research in Zambia which presents the context for the analysis reported in Section 5. 


\section{Agricultural performance and the agricultural budget in Zambia}

The agricultural sector in Zambia contributes $18 \%$ to the country's GDP. The sector also accounts for $67 \%$ of total employment and $25 \%$ of total exports (PRSP, 2006). Agricultural growth thus remains critical in the development of Zambia's economy and the agricultural sector is targeted to grow at 6\% per annum as opposed to the current $4.5 \%$ (Govereh, Shawa, Malawo \& Jayne, 2006:5; National Agricultural Policy, 2004-2015). Zambia’s agricultural sector is dominated by crop production, which accounts for more than $60 \%$ of total agricultural output (Kimhi \& Chiwele, 2000).

Despite the relative importance and potential of agriculture in Zambia, its performance in terms of crop production is not satisfactory, as food security problems have periodically continued to haunt the country (Bonaglia, 2008; Dorosh, et al., 2007). Between the years 1990 and 2005, output per unit area and per household regressed by $0.06 \%$ and $0.42 \%$ per annum, respectively (Govereh et al., 2008). It has been argued that “Zambia’s low crop productivity is partly attributed to misplaced spending priorities” (Govereh et al., 2009:9). Also, other studies (PRSP, 2002:57; Govereh et al., 2006) have partly attributed the low level of crop production to the reduction in investment and resource allocation inflows from the state budget and donor contributions to agriculture. It is highlighted that meagre financial resources to the sector have hindered programmes from increasing crop research and dissemination, and hence the failure to strategically position the sector according to its comparative advantage (PRSP, 2002:57).

Despite Zambia's commitment under the Maputo declaration, the Zambian government's budget allocation to agriculture has fluctuated between four and six percent of the total national budget. This is less than the $10 \%$ pledge made under the Maputo declaration and much less than the 15\% expenditure by Asian countries at the onset of the green revolution (Haggblade, 2007). Regrettably, Zambia remains short of its potential, in that its agriculture sector has underperformed when measured against variables such as the targeted growth rate, the land under cultivation, the area under irrigation and crop productivity.

Out of the six major items identified by Govereh et al. (2006) that comprise public expenditure on agriculture between 2001 and 2006, the poverty reduction programmes have the largest share of expenditure (about $48 \%$ ) and are of great importance to this study as they 
include, among other items, expenditure on agriculture research. It can be observed from Table 1 below that a greater proportion of funds (about $80 \%$ ) under the poverty reduction programme were spent on only two programmes, namely the Fertiliser Support Programme (FSP) and the Food Reserve Agency (FRA), while other programmes like agricultural research received less than one percent $(0.69 \%)$ of the total allocated funds, thereby effectively stagnating public agriculture research.

\section{Table 1: Budget allocations within the Poverty Reduction Programme 2001-2006 (real 2006 billion ZMK values)}

\begin{tabular}{|l|c|c|c|c|c|c|}
\hline Poverty Reduction Programmes & $\mathbf{2 0 0 1}$ & $\mathbf{2 0 0 2}$ & $\mathbf{2 0 0 3}$ & $\mathbf{2 0 0 4}$ & $\mathbf{2 0 0 5}$ & $\mathbf{2 0 0 6}$ \\
\hline Out-grower schemes & 0 & 22 & 10 & 2 & 1 & 2 \\
\hline Land and farm block development & 12 & 3 & 22 & 18 & 7 & 6 \\
\hline Farm institutes and training centre rehab & 0 & 9 & 4 & 1 & 3 & 2 \\
\hline Livestock restocking and disease control & 14 & 21 & 10 & 2 & 3 & 3 \\
\hline Fertiliser Support Programme & $\mathbf{6 9}$ & $\mathbf{5 3}$ & $\mathbf{7 3}$ & $\mathbf{8 8}$ & $\mathbf{1 4 9}$ & $\mathbf{1 9 9}$ \\
\hline Food Reserve Agency & $\mathbf{0}$ & $\mathbf{0}$ & $\mathbf{3 6 4}$ & $\mathbf{5 9}$ & $\mathbf{6 3}$ & $\mathbf{5 0}$ \\
\hline Fisheries development & 0 & 4 & 5 & 1 & 1 & 1 \\
\hline Rural investment fund & 44 & 11 & 3 & 2 & 2 & 1 \\
\hline Agriculture research & $\mathbf{0}$ & $\mathbf{4}$ & $\mathbf{1}$ & $\mathbf{2}$ & $\mathbf{2}$ & $\mathbf{1}$ \\
\hline Community extension & 0 & 0 & 0 & 1 & 2 & 1 \\
\hline Seed multiplication & 0 & 4 & 2 & 0 & 0 & 0 \\
\hline Other poverty reduction programmes & 0 & 8 & 12 & 2 & 4 & 4 \\
\hline Total & $\mathbf{1 3 9}$ & $\mathbf{1 3 8}$ & $\mathbf{5 0 5}$ & $\mathbf{1 7 8}$ & $\mathbf{2 3 7}$ & $\mathbf{2 7 0}$ \\
\hline
\end{tabular}

Source: Govereh et al., 2006

After a series of reforms and an acknowledgment of the importance of agriculture, the government's strategy to enhance the growth of the agricultural sector and reduce poverty among rural households is currently guided by the Fifth National Development Plan (FNDP) and the National Agricultural Policy (NAP) for the period from 2004 to 2015. The agricultural sector is targeted to grow at six percent per annum under this policy as opposed to the current $4.5 \%$. Therefore, government re-identified key areas of investment in agriculture in order to realise the desired growth rate. These include, among others, the agriculture service and technology development, the category in which research and development is now placed, and accounts for $11.9 \%$ of total agricultural expense, which is far more than the $0.69 \%$ allocated in earlier years. 
Nevertheless, Roseboom, Beintema and Mitra (2003:17) argue that increasing resources for agricultural technology is an indispensable but far from a sufficient condition for Africa to resolve its low productivity problems. The quantity of resources is as important as the quality of spending, in that resources must be used efficiently. The way that spending is disbursed could translate into achieving more with the same resources. Thurlow, Benin, Diao, Kalinda and Kalinda (2008) concluded that if resources were efficiently spent in Zambia, the country would need to allocate only eight percent of total government spending to the agricultural sector in order to achieve the six percent crop growth rate target of the Comprehensive African Agriculture Development Programme (CAADP). Failure to do so would mean that government would need to allocate $18 \%$ to achieve the same growth target.

According to Zambia’s National Agricultural Policy (2004-2015) regarding soils and crop research, the Republic of Zambia seeks to "generate and adapt technologies to increase production and to improve the management of agricultural research through appropriate planning, priority setting and budgeting” (MACO, 2004:19). Up to 2001, the Ministry of Agriculture and Cooperatives relied on incremental budgeting - the current year's budget equals the last year's budget adjusted for inflation. Since 2004, activity-based budgeting has been implemented, in which a budget is drawn up on the basis of the research activities that need to be implemented (MACO, 2008). However, with regard to priority setting in agriculture research, the formal tool that is used is scoring, in which researchers are required to rank crop research problems on an arbitrary scale. Such simplistic methods of prioritisation pose serious disadvantages such as: 1) vested interests of decision makers, which lead to research bias, 2) time variant properties of projects are not included in the evaluation, and 3) scales are not proportional to the financial measures of costs and benefits. Therefore simple approaches may not be efficient or may not reflect the broader policy objectives of the country’s agricultural research priorities.

The lack of an effective strategy and basis on which to set investments in agriculture to improve productivity is a problem for many African countries. Govereh et al., (2006:9) argue that policy makers in Zambia are also faced with the challenge of improving the efficiency of public expenditure on agriculture. Inasmuch as increased investments are necessary, national policy objectives will not be achieved merely by expanding the agricultural budget but also by increased efficiency in the use of resources. 


\section{Methodology}

This study uses the Dynamic Research Evaluation for Management (DREAM) model developed by the International Food Policy Research Institute (IFPRI) to quantify the economic benefits of crop research. These benefits were ranked to carry out the priority setting exercise. DREAM is based on the economic surplus approach which constitutes the most popular method used by economists to calculate and compare the benefits and costs of agriculture research. This kind of cost-benefit analysis could inform decision-makers on whether to implement new research programmes or continue with existing programmes, and to make choices from alternatives as well as formulate a basis for resource allocation and priority setting (Purdon et al., 2001). The change in consumer and producer surplus - a result of the outward shift in the supply function owing to technological change - is estimated. The research costs are incorporated in order to compute the internal rate of return (IRR) or the net present value (NPV) (Maredia et al., 2002).

The scope of this study was limited to field crops grown in Zambia. Seven crops were considered and the selection of these crops was based on their importance in terms of their contribution to the agricultural GDP, their dominance among producers, as well as the availability of data for the kind of analysis required for this study. The crops are maize, millet, sorghum, cotton, groundnuts, soya bean and sunflower.

\subsection{Data}

This study used both secondary and primary data, which consisted of market and technologyrelated variables. Secondary data for market related variables was accessed via requests made to authorities from the Ministry of Agriculture and Cooperatives (MACO) and from the Central Statistics Office (CSO). The data obtained included price and production data for maize, groundnuts, millet, sorghum, soya bean, sunflower and cotton for a three-year period (2004-2006), and the averages were used in order to even out extreme seasonal values. The production data obtained was disaggregated by farmer type (large and smallholder farmers) for each of the nine provinces of Zambia, which were further condensed into Zambia's four agro-ecological zones. Other secondary data obtained from various sources included commodity elasticity of supply and demand, income elasticity and GDP per capita. 
A survey was then conducted to obtain primary data in which a structured questionnaire was administered to all of the identified crop research institutions. These were: the Zambia Agriculture Research Institution (ZARI), the Zambia Seed Company (ZamSeed), the Seed Company (SeedCo), the Maize Research Institute (MRI), the Golden Valley Research Trust (GART), the Cotton Development Trust (CDT) and the University of Zambia (UNZA). The Directors of Research together with crop scientists within the institute were responsible for answering the questionnaire (one questionnaire for each research institution). In addition, due to the nature of the data required the human resources and finance departments also had to be consulted.

The purpose of the survey was twofold: firstly, it aimed to determine the nature and scope of crop research in Zambia and secondly, to elicit expert opinion on technology-related data for the empirical model. The variables for which data were obtained for each of the crops under consideration in this study included research costs, adoption levels and lags, and the expected change in crop yield and production costs, as well as the probability of research success attributed to research technologies.

\subsection{Empirical model}

The procedure outlined below draws extensively on work done by Alston et al. (1998) and Wood et al. (2001). The DREAM model is based on the assumption that investing in crop research generates cost-saving and yield-increasing technologies. This effect is modelled as a parallel shift in the supply curve to the right due to increased production. As a result of this research-induced supply shift, it follows that the market prices of commodities will fall; therefore, consumers can consume more of the commodity at this lower price and are better off. Producers are also better off because of increased yields. Equilibrium is defined through market clearing conditions at the new levels of production, consumption and price (Wood et al., 2001).

The change in producer and consumer surplus for a research-induced supply shift of a particular commodity in a multiple horizontal market in year $t$ can then be estimated with the following formulae (Alston et al., 1998:389): 


$$
\begin{aligned}
& \Delta P S_{j t}=\left(K_{j t}+p p_{j t}^{R}-p p_{j t}\right)\left(Q_{j t}+0.5\left[Q_{j t}^{R}-Q_{j, t}\right]\right) \\
& \Delta C S_{j t}=\left(p c_{j t}-p c_{j t}^{R}\right)\left(C_{j t}+0.5\left[C_{j t}^{R}-C_{j t}\right]\right)
\end{aligned}
$$

Where:

$\mathrm{PP}_{\mathrm{t}} \quad$ Producer price prior to research-induced supply shift

$\mathrm{PP}_{\mathrm{jt}}^{\mathrm{R}} \quad$ Producer price after research-induced supply shift

$\mathrm{Q}_{\mathrm{jt}} \quad$ Pre-research producer quantity in year $t$

$\mathrm{Q}_{\mathrm{jt}}{ }^{\mathrm{R}} \quad$ Post-research producer quantity in year $t$

$\mathrm{pc}_{\mathrm{jt}} \quad$ Commodity price prior to research-induced supply shift

$\mathrm{pc}_{\mathrm{jt}}^{\mathrm{R}} \quad$ Commodity price after research-induced supply shift

$\mathrm{C}_{\mathrm{jt}} \quad$ Pre-research consumer quantity in year $t$

$\mathrm{C}_{\mathrm{jt}}^{\mathrm{R}} \quad$ Post-research consumer quantity in year $t$

$\mathrm{K}_{\mathrm{jt}} \quad$ Supply curve shift downwards in period $t$, due to research

The magnitude of the shift in the supply curve induced by research (K-factor in equation (1) above) is important in determining the total research benefits. This crucial variable $\mathrm{K}$ is a function of the expected change in yield, assuming research is successful; the proportionate change in variable costs to achieve the expected yield change; the probability of research success (that research will achieve the expected yield change); the adoption rate and the depreciation of the technology. The equation for determining $\mathrm{K}$ is as follows (Alston et al., 1998: 380):

$$
K_{j t}=\left[\begin{array}{ll}
\frac{E(Y)}{e_{j}} & \frac{E(C)}{E(Y)}
\end{array}\right] p A_{t}\left(1 \quad \delta_{t}\right)
$$

Where:

$\mathrm{E}\left(\mathrm{Y}_{j}\right)$ Expected change in yield after new technology adoption

$\mathrm{e}_{\mathrm{j}} \quad$ Commodity supply elasticity 
$\mathrm{E}\left(\mathrm{C}_{j}\right)$ Proportionate change in variable costs per hectare to achieve the expected yield change

pj Probability of research success

At Adoption rate

$\delta_{\mathrm{t}} \quad$ Depreciation factor

The expected future growth of the underlying supply curves were endogenously projected by the model after adjusting for any exogenous growth in supply and taking into account the adoption levels as well as adoption lags such that the shift in supply (K) was attributed to research-induced productivity. This resulted in a new equilibrium price and quantity at which the producer and consumer surplus measures were computed and discounted at $8 \%$ discount rate to the base year, and the cost of research was subtracted to determine the net present value benefits. The period of analysis for this ex ante study was from 2005 to 2020, using 2005 as the base year. The analysis was for a multiple horizontal market economy with no spill-over effects of research from neighbouring countries in the region.

\section{Crop research in Zambia}

Before presenting the empirical findings from the model, we first provide a brief summary of the nature and scope of the crop research system in Zambia so as to gain greater understanding of the findings of the empirical model.

The institutions conducting crop research in Zambia consist of the Zambia Agriculture Research Institution (ZARI) which is the major government research institution with nine auxiliary research institutions distributed in each province of the country. Then there are the private research institutions such as the Zambia Seed Company (ZamSeed), the Seed Company (SeedCo), and the Maize Research Institute (MRI). Two research trusts, the Golden Valley Research Trust (GART) and the Cotton Development Trust (CDT) are also involved in crop research while the University of Zambia (UNZA) is the single tertiary institution conducting crop research. These crop research institutions identified are still the same institutions that existed about a decade ago. This is not surprising as new research entities or arrangements do not always occur often in many countries, and when they do, this can be 
seen as a measurement of instability. Therefore, the fact that no new research institutions have been established in Zambia in the past decade indicates stability in agricultural research management.

The total number of crop researchers in terms of Full Time Equivalents (FTEs) in 2009 was 161 FTEs, representing a 40\% increase in the number of crop researchers between 2004 and 2009. This increase was mainly attributed to the government research institutions, which recruited 39 FTE researchers between 2005 and 2008 after undergoing an employment freeze that ended in 2004. Similarly, expenditure on crop research also increased steadily over the same period, from ZMK 16 billion in 2004 to about ZMK 29 billion in 2009. The increase in the overall total crop research expenditure is also largely attributed to the government. Government expenditure increased by $80 \%$ in 2007 as a result of the advent of the country's Fifth National Development Plan (FNDP), which advocates for increased financial resources to the agriculture sector and particularly to agriculture research and technology development (MACO, 2008). In addition, the increase in expenditure by the government was due to the fact that government recruited more research personnel over the same period. It was also observed that expenditure by the private sector increased consistently. The major sources of funds for public institutions was the government, while research trusts and higher learning institutions obtained most of their funds from international donors, and the private sector funded its own research entirely.

In terms of crop coverage, these institutions varied in crop focus, ranging from one research crop to as many as seven crops. Crops for which research activities were reported include soya beans, maize, sorghum, millet, sunflowers, cotton, groundnuts, wheat, mixed beans and cassava. The less popular crops are cowpeas, sun hemp and guar. However, it was evident that maize was the major research crop as all the research institutions (except for the Cotton Development Trust) had on-going maize research programmes. It was also found that maize is the crop with the largest budget allocation and the largest number of FTE researchers.

\section{Results from the empirical model}

The data was analysed using the DREAM programme, which essentially matches marketrelated variables to technology data in order to compare benefits and costs. While marketrelated data was obtained from secondary sources, the data required for the computation of 
the research-induced supply shift (K-value) (technology data) was based on expert opinion elicited from researchers. The data was analysed as follows:

- The scenario page was selected to enter the commodity name associated with the scenario, in this case maize, sorghum, millet, groundnuts, sunflowers, soya beans and cotton. Still under the scenario page, the regions of production were also defined, firstly in terms of all of the nine provinces of Zambia, after which the provinces were assigned to agro-ecological zones. The discount rate (8\%), simulation period (15 years) and base year (2005) were also entered.

- Market data - production data was entered for the base year, disaggregated by farmer type (smallholder and large-scale) for each province. Aggregate consumption data for each commodity, price data for each commodity at the provincial level, and the elasticity of demand and supply as well as data pertaining to exogenous growth variables (GDP per capita and income elasticity) were all captured in the respective slots.

- Research data - the probability of research success, the anticipated change in yield and the change in variable costs of production were entered for each commodity. Also, the adoption path (linear) was selected, after which data pertaining to the time expected to elapse from release of a new technology until maximum adoption and the maximum adoption level for each crop and for each farmer group was entered. The cost of the research (obtained from research institutions) was entered.

To analyse each scenario (commodity), the model was run for a simulation period of 15 years. This was repeated for each commodity, after which scenarios were ranked based on the net present values obtained.

\subsection{Aggregate research benefits}

Based on Net Present Value (NPV) benefits computed from the DREAM model, maize was found to have the highest net present value benefit for the period from 2005 to 2020 for research investments made in 2005 and therefore ranked first. This was followed by soya beans, groundnuts, cotton, millet, sunflowers and lastly, sorghum (Table 2 below). 
Table 2: Capital budgeting results for crop research investment

\begin{tabular}{|l|c|c|c|c|}
\hline Crop & $\begin{array}{c}\text { Total NPV (ZMK' } \\
\text { Million) }\end{array}$ & IRR ( \%) & Benefit/Cost & Ranking \\
\hline Maize & 114360 & 52.4 & 14.25 & 1 \\
\hline Soya beans & 13161 & 22.3 & 25.64 & 3 \\
\hline Groundnuts & 7186 & 15.1 & 86.14 & 4 \\
\hline Cotton & 5219 & 11.9 & 21.68 & 5 \\
\hline Millet & 1284 & 21.5 & 42.80 & 6 \\
\hline Sunflowers & 1140 & 13.0 & 21.92 & 7 \\
\hline Sorghum & 930 & 10.3 & 6.59 & 2 \\
\hline
\end{tabular}

1 US\$=ZMK 4500

Source: own compilation DREAM

The computed internal rates of return were found to be greater than the cost of investment, while the benefit-cost ratios were greater than one for all crops. Therefore, investing in crop research was a worthwhile investment at a discount rate of $8 \%$. This concurs with earlier findings in other regions that investing in crop research (and other public goods) was worthwhile and would be more advantageous when compared to investing in private input subsidies (Lopez, 2006; Jayne et al., 2007:11).

When actual investment in crop research was compared to returns on investment for each crop for the period under consideration (Table 3 below), it was observed that maize had the highest returns and also had the highest financial expenditure, implying that resources to this crop were efficiently allocated. It is not surprising that maize ranked first in terms of net present value benefits. This is because all of the investment, marketing and export policies in the country have always favoured the production of this crop. It is also worth noting that all the identified crop research institutions, except the Cotton Development Trust, perform research in maize, and have released more than 16 improved maize varieties since 1992 (ZARI, 2009). According to the survey, improved maize varieties were the most widely adopted, with adoption levels higher than $60 \%$ for both smallholder and large-scale farmers. 
Table 3: Resource expenditure compared against returns to investment

\begin{tabular}{|l|c|c|}
\hline \multirow{2}{*}{ Crop } & \multicolumn{2}{|c|}{ Crop Rank by } \\
\cline { 2 - 3 } & $\begin{array}{c}\text { Financial resource } \\
\text { Allocation }\end{array}$ & $\begin{array}{c}\text { Returns on Investment } \\
\text { (Based on DREAM } \\
\text { NPV results) }\end{array}$ \\
\hline Maize & 1 & 1 \\
\hline Soya beans & 4 & 2 \\
\hline Cotton & 2 & 4 \\
\hline Sorghum & 3 & 7 \\
\hline Groundnuts & 5 & 3 \\
\hline Sunflowers & 6 & 6 \\
\hline Millet & 7 & 5 \\
\hline
\end{tabular}

Source: own survey data and DREAM

For the rest of the crops in Table 3 above, financial allocations did not necessarily match returns on investment. Although sorghum ranked third in terms of the total budget allocation, it had the lowest return on research investment. Such an outcome was observed because of public crop research conducted by the government, whose social objective (such as equity, food security, drought-tolerant crops) is also important, therefore crops with low returns still received higher funding. In Zambia, the diversification to and promotion of sorghum, millet and cassava research remains government's core strategy for ensuring food security by encouraging the growth of drought-tolerant crops in the face of climate variability (CEEPA, 2006; Govereh, 2007).

The need for the government to protect the vulnerable in society by promoting less efficient programmes is a familiar practice in many countries, but the extent to which efficiency is given up in order to achieve social objectives is most crucial and the lack of strategy on how this trade-off ought to be done is perhaps the reason for slow agriculture growth today in most poor countries like Zambia.

In this regard, the private sector could play a vital role in ensuring efficiency in crop research by performing research in profitable crops, thereby allowing the government to conduct research on crops based on social objectives. However, this public private partnership must 
be well coordinated. For example, during the era of structural reform (1993 - 1997), the Zambian Government optimistically assumed that the private sector would take up research responsibility for commercial crops with potential for high profit and as a result, dropped some crops (oilseeds, tea, coffee and flowers) from regional public research programme priority lists. However, this did not take place as planned since, until recently, the private sector has been reluctant to invest in crop research. This is because the government had overlooked the need for implementing the Plant Breeders' Rights Act that would ensure an enabling environment to complement such reform. In response, the Plant Breeders' Rights Act was drafted and completed in 1999 but had not yet been implemented at the time of this study, as government is still carrying out further consultation (ZARI, 2009).

\subsection{Crop priorities by farmer type}

When crop priorities were disaggregated on the basis of farm size, the model revealed that the top three crops for large-scale farmers were maize, soya beans and sunflowers (Table 4). The model results make sense in that the choice of crops by large-scale farmers is aligned with the export market and local agro-processing industries such as grain milling, seed oil extraction and livestock feed processing, which constitute the major crop processing industries in Zambia.

Table 4: Net present values for large and smallholder farmers

\begin{tabular}{|l|c|c|}
\hline Crop & $\begin{array}{c}\text { Large farmer Surplus } \\
\text { NPV } \\
\text { (ZMK’ Million) }\end{array}$ & $\begin{array}{c}\text { Smallholder farmer Surplus } \\
\text { NPV } \\
\text { (ZMK’ Million) }\end{array}$ \\
\hline Maize & 30930 & 46093 \\
\hline Soya beans & 7523 & 141 \\
\hline Groundnuts & 299 & 2688 \\
\hline Cotton & 219 & 2656 \\
\hline Millet & 281 & 569 \\
\hline Sunflowers & 351 & 185 \\
\hline Sorghum & 280 & 592 \\
\hline
\end{tabular}

Source: own compilation based on DREAM results

Crop priorities for smallholder farmers included maize, groundnuts and cotton in agroecological zones I and II, while the model revealed that crop priorities for smallholder farmers in region III were maize, groundnuts and small grains (sorghum and millet). 
Groundnuts are widely grown by smallholder farmers across the country because apart from being a good source of protein, groundnuts are often grown in rotation with maize for their nitrogen-fixing properties in the soil. This is advantageous to smallholder farmers, who use inorganic fertilisers in limited amounts. The production of cotton by smallholder farmers on the other hand, is influenced by the presence of private companies that promote cultivation of cotton via out-grower schemes. Cotton (and soya bean) production by smallholder farmers is only viable with the support of proper institutional arrangements that ensure the provision of inputs, credit facilities, extension services and a market for the crop. The success of cotton research is therefore heavily influenced by such complementary institutions and organisations that facilitate adoption of the technology by farmers. Consequently, it is difficult to isolate the contribution of research from complementary institutions and or policies that enhance adoption.

\subsection{Distributional benefits}

Even though crop priority setting in this study was based on the objective of efficiency only, it was necessary to examine how these benefits are distributed among different farmer types. To undertake this analysis, the net present values computed by the model for each farmer group were expressed as a percentage of the total aggregate net present value benefits (Table 5 below).

In the case of maize, $20 \%$ of the total net present value benefits accrued to large-scale farmers in the central province. This was followed by smallholder farmers in the eastern and southern provinces at $16 \%$ and $13 \%$, respectively. While all the benefits of soya bean production were accrued by large-scale farmers, most of the benefits for groundnuts and cotton were accumulated by smallholder farmers.

Also, it is worth noting that smallholder farmers located in the southern, central and eastern regions of Zambia accrued much higher benefits than smallholder farmers in other regions. This is because crop production is driven by more than just favourable climatic conditions as these regions also contain the country's major road and railway infrastructure. The availability of transport infrastructure in these regions not only reduces transaction costs for producers but also ensures that markets are readily available and accessible. This therefore 
indicates the need for increased infrastructure development in other regions especially in the rural areas.

Table 5: Distributional benefits for farmer types at provincial level

\begin{tabular}{|c|c|c|c|c|c|c|c|}
\hline Farmer type & Groundnuts & Maize & Millet & Sorghum & Soya Beans & Sunflowers & Cotton \\
\hline Central Small & $6 \%$ & $10 \%$ & $3 \%$ & $9 \%$ & $-1 \%$ & $4 \%$ & $19 \%$ \\
\hline Central Large & $0 \%$ & $20 \%$ & $29 \%$ & $0 \%$ & $38 \%$ & $10 \%$ & $1 \%$ \\
\hline Copperbelt Large & $0 \%$ & $9 \%$ & $0 \%$ & $0 \%$ & $35 \%$ & $0 \%$ & $0 \%$ \\
\hline Eastern Small & $25 \%$ & $16 \%$ & $2 \%$ & $4 \%$ & $-4 \%$ & $33 \%$ & $58 \%$ \\
\hline Luapula Large & $0 \%$ & $0 \%$ & $0 \%$ & $0 \%$ & $0 \%$ & $0 \%$ & $0 \%$ \\
\hline Lusaka Small & $1 \%$ & $3 \%$ & $0 \%$ & $0 \%$ & $0 \%$ & $0 \%$ & $1 \%$ \\
\hline Lusaka Large & $0 \%$ & $5 \%$ & $0 \%$ & $2 \%$ & $16 \%$ & $8 \%$ & $0 \%$ \\
\hline Northern Small & $30 \%$ & $7 \%$ & $48 \%$ & $5 \%$ & $-1 \%$ & $6 \%$ & $0 \%$ \\
\hline Northern Large & $0 \%$ & $0 \%$ & $0 \%$ & $0 \%$ & $0 \%$ & $1 \%$ & $0 \%$ \\
\hline $\begin{array}{l}\text { North-western } \\
\text { Small }\end{array}$ & $6 \%$ & $2 \%$ & $1 \%$ & $22 \%$ & $0 \%$ & $0 \%$ & $0 \%$ \\
\hline Western Small & $2 \%$ & $3 \%$ & $7 \%$ & $31 \%$ & $0 \%$ & $0 \%$ & $0 \%$ \\
\hline Western Large & $0 \%$ & $0 \%$ & $0 \%$ & $1 \%$ & $0 \%$ & $0 \%$ & $0 \%$ \\
\hline Total & $100 \%$ & $100 \%$ & $100 \%$ & $100 \%$ & $100 \%$ & $100 \%$ & $100 \%$ \\
\hline
\end{tabular}

Source: Own compilation based on DREAM results

The model also showed that consumers benefited from investing in crop research. As a result of the research-induced supply shift, production increased and equilibrium price decreases, hence the quantity consumed increased thereby increasing consumers' welfare.

According to the results obtained from the model, when consumption 'without' the researchinduced supply shift was compared to consumption 'with' the research-induced supply shift, it was revealed that consumption of groundnuts, millet and sorghum 'with' the researchinduced supply shift increased by $10 \%, 11 \%$ and $3 \%$, respectively. The consumption of 
sunflower, maize and cotton also increased, by $62 \%, 55 \%$ and $26 \%$, respectively, while consumption of soya beans almost doubled. The model therefore illustrated that soya beans, sunflowers, maize and cotton are more responsive to a price change. This is not surprising, because these crops are important primary inputs for Zambia’s agricultural industries and are thus more affected by market price changes as opposed to crops produced for subsistence consumption, which would not be much influenced by market prices.

\section{New priorities for crop research in Zambia}

Crop productivity remains low in Zambia and one of the impediments among other constraints is the challenge of improving the efficiency of expenditure in agriculture research in order to increase crop productivity and to strategically position the sector according to its comparative advantage. In this study, positive net present values were obtained for all crops under consideration. In addition, the internal rates of return were greater than one for the simulated period (2005-2020). Therefore investing in agriculture crop research in Zambia is worthwhile and the public and private sectors as well as international organisations should increase investments in Zambia’s crop research.

Based on the findings, further investments should be made in maize research as it yields the highest returns and benefits for both large-scale and smallholder farmers. Also, maize is the country's staple crop and further investments in maize research would provide a greater understanding of the dynamics of the maize-based farming system. Other crops for research investment are soya beans, cotton, groundnuts and sunflowers. The results obtained from this study could serve as a basis for a strategic guide for future investments into crop research, and subsequently assist with the establishment of a crop-based research system that is efficient and more rewarding.

The allocation of financial resources towards crop research was not efficient for all crops, as some crops receiving high investment did not necessarily have higher net present value benefits. For instance, while sorghum ranks third in terms of the total financial resource allocation, it had the least returns on investment. This therefore demands re-allocations of financial resources between crops in favour of crops with high returns. However, such adjustment may not be easily attained because the government still conducts the bulk of research in Zambia, and it caters for other social objectives such as equity and drought 
tolerance, and hence the need to diversify its expenditure to less efficient crops such as sorghum and millet. Nonetheless, the extent to which social objectives supersede efficiency must be addressed strategically without compromising economic development. Also, importantly, increasing and using research funds more efficiently would broaden the spectrum of research crops under consideration without necessarily shifting resources from staple priority crops such as maize, thus including other crops such as millet, sorghum, rice, wheat and potatoes. These and other crops could contribute to the country's food security directly or indirectly through increased farmer incomes.

It was also deduced that crop research investment influences the distribution of welfare benefits on different producer groups. The study further established that smallholder farmers in some regions were among the groups that received the highest proportion of benefits, even for crops such as maize whose financial resources were efficiently allocated towards research. Therefore, the objective of efficiency may not necessarily leave smallholder farmers worse off, as long as they have access to complementary infrastructure and institutions for agriculture production. This distributive aspect attained from the choice of crop research investment can serve as a crucial policy instrument for policy makers in targeting specific producer and consumer groups.

The state's role in facilitating the success of research and technology development and dissemination is mainly through good governance. In this regard, the following aspects must be given greater attention.

- Given that the intellectual property rights policy for plant breeders still needs enforcement, the Government of Zambia must act promptly to implement this act. This will create an enabling environment for private sector participation in agriculture crop research and will coerce the private sector and international partners to make further investments in crop research. Increased participation by the private sector and international organisations in crop research will allow these institutions to invest in crops with high returns while the government could focus on crops with social benefits.

- The distributional benefits showed that smallholder farmers, particularly in the northern and western provinces, which have relatively worse infrastructure, benefited less than their counterparts in other provinces. Increased productivity growth from 
released technologies without complementary infrastructure and institutional arrangements may prove to be counterproductive. As such, there is need for major investment in transport infrastructure, research stations, storage facilities, telecommunications and market facilities. Apart from the physical hardware, there is also a need to strengthen the institutional set-up of, for example, intellectual property rights, contract enforcement, credit facilities, market information (demand, supply, prices, grades and standards) and increased transparency.

- There is a need for the government to continue to secure financial resources to increase investment in public agriculture research with high returns, as opposed to overspending on recurrent subsidies (such as the Fertiliser Support Programme) that render only quick, short-term benefits. If soil fertility is the problem, it would be more beneficial in the long term to invest in soil fertility technologies and environmentally compatible farming systems, such as conservation farming, that foster sustainable development.

\section{Conclusion}

This paper presented results that are only indicative of what the strategic decision on priority setting should look like. Yet, it is essential that research managers and policy-makers incorporate the findings and recommendations from this study by expanding expenditure on crop research as this increases the welfare of the Zambian farmers and consumers. In addition to increasing expenditure, the right crop research priorities will improve the quality of spending and would broaden the spectrum of research. In particular, financial resources need to be re-allocated between crops; from low-return crops to crops with high returns, in order to improve efficiency. Given that other objectives (such as social and equity objectives) may be equally important for the government, proper coordination of research with the private sector (Public Private Partnerships) will remain inevitable for an effective and competitive agricultural sector in Zambia. 


\section{References}

Alston, J., Norton, G. and Pardey, P. 1998. Science under scarcity: Principles and practice for agriculture. New York: Cornell University Press.

Bonaglia, F. 2008. Zambia: sustaining agricultural diversification. Organisation for Economic Co-operation and Development (OECD). [Online] Available at: http://www.oecd.org/dev/publications/businessfordevelopment.

CEEPA (Centre for Environmental Economics and Policy in Africa). 2006. Climate change and African agriculture. University of Pretoria, Pretoria: CEEPA Policy Note No. 27.

Dorosh, P., Dradri, S. and Haggblade, S. 2007. Alternative instruments for ensuring food security and price stability in Zambia. Lusaka: FRSP working paper No. 29. [Online] Available at: http://www.aec.msu.edu/fs2/zambia/wp_29.pdf [Accessed: 2008-07-20].

Govereh, J., Malawo, E., Lungu, T., Jayne, T., Chinyama, K. and Chilonda, P. 2009. Trends and spatial distribution of public agricultural spending in Zambia: Implications for agricultural productivity growth. Lusaka: Food Security Research Project (FSRP) Working Paper No. 36.

Govereh, J., Shawa, J., Malawo, E. and Jayne, T. 2006. Raising the productivity of public investments in Zambia’s agricultural sector. Lusaka: Food Security Research Project (FSRP) Working Paper No. 20. [Online] Available at: http://www.aec.msu.edu/agecon/fs2/zambia/index.htm [Accessed: 2008-03-09].

Griliches, Z. 1958. Research costs and social returns: Hybrid corn and related innovations. Journal of Political Economy, 66:419-431.

Haggblade, S. 2007. Returns to investment in agriculture. Lusaka: Food Security Research Project (FSRP) Policy Synthesis No. 19. [Online] Available at: http://wwwaec.msu.edu/agecon/fs2/zambia/index.htm [Accessed: 2008-08-21]. 
Jayne, T., Govereh, J., Chilonda, P., Mason, N., Chapoto A. and Haantuba, H. 2007. Trends in agricultural and rural development indicators in Zambia. FSRP Working Paper No. 24. [Online] Available at: http://www.aec.msu.edu/fs2/zambia/wp_24.pdf [Accessed: 2009-0419].

Kimhi, A. and Chiwele, D. 2000. Barriers for development in Zambian small and medium size farms: Evidence from micro-data. American Agricultural Economics Association.

MACO (Ministry of Agriculture and Cooperatives). 2004. National Agricultural Policy 20042015. Lusaka: Government of the Republic of Zambia (GRZ).

Norton, G.W., Ganoza, V.G. and Pomareda, C. 1987. Potential benefits of agricultural research and extension in Peru. American Journal of Agricultural Economics, 69(2):247-57.

Parker, S. (n.d). Agricultural Lending Practices: Methodologies and Programs. Lusaka, Zambia: Cooperative League of the United States of America (CLUSA).

PRSP (Poverty Reduction Strategy Paper). 2002. Zambia: Poverty Reduction Strategy Paper 2002-2004. Lusaka: Ministry of Finance and National Planning.

Roseboom, J., Beintema, N. and Mitra, S. 2003. Building impact oriented R\&D institutions. Inter Academy Council (IAC) Background Paper No. 3.

Siegel, P.B. and Alwang, J. 2005. Poverty Reducing Potential of Smallholder Agriculture in Zambia: Opportunities and Constraints Africa Region. Washington, D.C., USA: World Bank Working Paper Series No. 85.

Thurlow, J., Benin, S., Diao, X., Kalinda, H. and Kalinda, T. 2008. Agricultural growth and investment options for poverty reduction in Zambia. Washington, D.C.: International Food Policy Research Institute (IFPRI) Discussion Paper 00791. 
Wood, S., You, L. and Baitx, W. 2001. User Manual for Dynamic Research Evaluation for Management (DREAM). Washington, D.C.: International Food Policy Research Institute (IFPRI).

ZARI (Zambia Agriculture Research Institution). 2009. Ministry of Agriculture and Cooperatives: Brief. Lusaka: ZARI. 